\title{
Erratum to: Identification of novel CSF biomarkers for neurodegeneration and their validation by a high-throughput multiplexed targeted proteomic assay
}

Wendy E. Heywood ${ }^{1,5}$, Daniela Galimberti ${ }^{2}$, Emily Bliss ${ }^{1}$, Ernestas Sirka ${ }^{1}$, Ross W. Paterson ${ }^{3}$, Nadia K. Magdalinou ${ }^{4}$, Miryam Carecchio ${ }^{5}$, Emma Reid ${ }^{1}$, Amanda Heslegrave ${ }^{3}$, Chiara Fenoglio ${ }^{2}$, Elio Scarpini ${ }^{2}$, Jonathan M. Schott ${ }^{3}$, Nick C. Fox ${ }^{3}$, John Hardy ${ }^{3}$, Kailash P. Bhatia ${ }^{3}$, Simon Heales ${ }^{1,6}$, Neil J. Sebire ${ }^{6}$, Henrik Zetterberg ${ }^{3,7}$ and Kevin Mills ${ }^{1,6^{*}}$

After publication of this work [1], we noted that the names of two authors Kailash Bhatia and Henrik Zetterberg had been misspelled. The names have now been corrected above.

\begin{abstract}
Author details
${ }^{1}$ Centre for Translational Omics, University College London Institute of Child Health, 30 Guilford Street, London WC1N 1EH, UK. ${ }^{2}$ Neurology Unit, Department of Pathophysiology and Transplantation, University of Milan, Fondazione Cà Granda, IRCCS Ospedale Policlinico, Via F.Sforza 35, 20122 Milan, Italy. ${ }^{3}$ Dementia Research Centre, University College London Institute of Neurology, London, UK. ${ }^{4}$ Reta Lila Weston Institute of Neurological Studies, UCL Institute of Neurology, Queen Square, London, UK.

${ }^{5}$ Neuropediatrics Unit, IRCCS Istituto Neurologico Carlo Besta, Milan 20133, Italy. ${ }^{6}$ Great Ormond Street Hospital for Children, London WC1N 3JH, UK. ${ }^{7}$ Clinical Neurochemistry Laboratory, Institute of Neuroscience and Physiology, Department of Psychiatry and Neurochemistry, The Sahlgrenska Academy, University of Gothenburg, 43180 Mölndal, Sweden.
\end{abstract}

Received: 18 February 2016 Accepted: 18 February 2016 Published online: 23 February 2016

\section{Reference}

1. Heywood WE, Galimberti D, Bliss E, Sirka E, Paterson RW, Magdalinou NK, et al. Identification of novel CSF biomarkers for neurodegeneration and their validation by a high-throughput multiplexed targeted proteomic assay. Mol Neurodegener. 2015;10:64. Epub 2015/12/03.

\footnotetext{
*Correspondence: kevin.mills@ucl.ac.uk

Wendy E. Heywood and Daniela Galimberti as joint first author. Henrik Zetterberg and Kevin Mills as joint last author.

${ }^{1}$ Centre for Translational Omics, University College London Institute of Child Health, 30 Guilford Street, London WC1N 1EH, UK

${ }^{6}$ Great Ormond Street Hospital for Children, London WC1N 3JH, UK

Full list of author information is available at the end of the article
}

Submit your next manuscript to BioMed Central and we will help you at every step:

- We accept pre-submission inquiries

- Our selector tool helps you to find the most relevant journal

- We provide round the clock customer support

- Convenient online submission

- Thorough peer review

- Inclusion in PubMed and all major indexing services

- Maximum visibility for your research

Submit your manuscript at www.biomedcentral.com/submit
() Biomed Central 